\title{
ENTRE LA ESPADA Y LA PARED: AGRICULTORES FAMILIARES EN LA ZONA OCCIDENTAL DEL VALLE CENTRAL DE COSTA RICA
}

\author{
BETWEEN A ROCK AND A HARD PLACE: FARM-FAMILIES IN THE \\ WESTERN CENTRAL VALLEY REGION OF COSTA RICA
}

\author{
Joanna Dreby* \\ Fátima Guadalupe Rodríguez Pacas**
}

RESUMEN

\begin{abstract}
Este artículo explora las formas de adaptación al estado de la economía agrícola del siglo XXI asumidas por pequeños agricultores familiares en la región occidental del Valle Central de Costa Rica. El análisis se basa en una investigación llevada a cabo en julio-diciembre de 2017, con una metodología cualitativa a través de las técnicas de participación-observación y entrevistas a 56 miembros de familias productoras de 32 fincas. Los resultados indican que los productores convierten el proyecto de la finca en un pasatiempo o una labor a medio tiempo; o bien, intercambian de labor al insertarse en mercados de turismo, educación al consumidor y productos de valor agregado.
\end{abstract}

PALABRAS CLAVE: COSTA RICA * ECONOMIA AGRARIA * FAMILIA * PRODUCCIÓN AGRICOLA * MERCADO AGRICOLA

ABSTRACT

The goal of this article is to explore, qualitatively, the ways in which farm-families located in the western Central Valley region of Costa Rica adapt to the state of the $21^{\text {st }}$ century agricultural economy. The analysis draws on fieldwork from July to December 2017 and on interviews with 56 family members operating 32 small to mid-sized farms. Results suggest that either producers convert the farm project into a hobby, a part-time occupation or they fundamentally change the operations to insert themselves into new markets of tourism, education and the sale of value-added products.

KEYWORDS: COSTA RICA * AGRARIAN ECONOMY * FAMILY * AGRICULTURAL PRODUCTION * AGRICULTURE MARKET

Universidad Estatal de Nueva York, Albany, Estados Unidos.

jdreby@albany.edu

** Universidad Estatal de Nueva York, Albany, Estados Unidos.

frodriguezpacas@albany.edu 


\section{INTRODUCCION}

Las condiciones estructurales que marcan la integración vertical y horizontal de los mercados agrícolas han favorecido a los grandes productores $y$ han reducido los espacios de participación para los pequeños y medianos agricultores familiares a nivel local, tanto en territorio costarricense como a nivel mundial (Bailey et al., 2014; Constance et al., 2014; Hendrickson et al., 2017; Samper, 2010; Thu, 2009). Durante la segunda mitad del siglo xx, la organización agrícola del mercado global debilitó a los productores familiares en contextos geográficos diversos (Bailey et. al., 2014; Gray, 2013; Pilgeram, 2011). A pesar de que el Estado costarricense ha implementado algunas medidas proteccionistas para la producción familiar y el mercado interno, también se ha adentrado en un proceso de mayor internacionalización agrícola con la apertura y liberalización de la economía agraria y el turismo. Asimismo, se ha integrado a una dinámica económica agrícola y global que debilita a la agricultura familiar (Mora-Alfaro, 1989).

Este proceso de liberalización agraria se consolidó a finales de siglo, con la adopción de medidas de ajuste estructural de corte neoliberal que condujeron, posteriormente, a la adhesión de Tratados de Libre de Comercio o TLC (Mora-Alfaro, 2013; Vargas, 2004) Así, la política económica se enfocó en estimular la producción para el mercado exterior mientras dejaba en una posición marginal al campesino y también al pequeño productor, al promover una realidad agrícola que profundizó la exclusión del sector de productores familiares (Alvarado, 2018; Arias, 2005; Fernández, 1989; Mora-Alfaro, 1989, 2005, 2013; Rodríguez et al., 2018).

En el nuevo siglo se evidencia la generación de un fuerte vínculo entre el productor familiar y la industria turística, que tiene como consecuencia un cambio en la forma en la que el consumidor valoriza los productos agrícolas, ya que ha emergido una concientización colectiva que valora más lo que está producido localmente con ética y métodos sostenibles (Schor y Thompson, 2014). Los diferentes roles asumidos por los miembros de la familia se convierten en elementos de significativo valor durante el proceso de producción.
Por ejemplo, se le asigna más valor a la comida producida localmente en cultivos familiares $y$ ecológicos que a la comida producida a gran escala en una finca industrializada con contratos mal pagados y muchas veces suponiendo explotación laboral. Por lo tanto, se han abierto nuevos espacios para los agricultores familiares, que pueden considerarse, en cierta medida, una oportunidad (Gray, 2013; Schor, 2011; Schor y Thompson, 2014; Sick, 2008). Así, los agricultores familiares se encuentran en una coyuntura única, donde se supone que pueden ser actores principales y asumir una mayor participación en la actual economía emergente, con la presunción de que el consumidor se encuentra de su lado. De esta manera, surgen los siguientes cuestionamientos desde la perspectiva de la familia como unidad productiva: ¿cómo se posicionan en su conjunto los pequeños agricultores familiares de Costa Rica respecto a las fuerzas económicas que los debilitan y que también les abren nuevas oportunidades? ¿qué tipos de restricciones sienten y que decisiones toman al respecto?

Este artículo presenta una exploración cualitativa desarrollada durante 6 meses de observación participativa, que incluyó los testimonios de 56 agricultores familiares, en su gran mayoría propietarios de 32 fincas localizadas, principalmente, en la región occidental del Valle Central de Costa Rica ${ }^{1}$. El objetivo del estudio es indagar cómo estos agricultores, como unidad productiva familiar, se posicionan y se adaptan frente a la economía agraria que aún privilegia los mercados internacionales, pero que presenta como variante el otorgamiento de mayor valía al proceso de producción y venta, no solo al producto en sí mismo. En esta investigación interesan las decisiones de la familia como unidad productora, no un específico tipo

$1 \quad$ Para mantener la confidencialidad de los datos se mantendrá el anonimato de las personas participantes y se referenciará como entrevistado 1 , entrevistado 2, entrevistado 3 en el caso de las entrevistas formales y comunicación personal en el caso de entrevistas informales que ocurrieron durante el transcurso del trabajo de campo. Entrevistas formales e informales se realizaron entre julio y diciembre del año 2017. 
de producto agrícola que cultivan y venden; se consideran más bien los testimonios de las familias productoras sin importar el sector agrícola al cual se dedican.

Como se demuestra en las entrevistas, la mayoría de los agricultores se describen en una posición condicionada que los deja entre la espada y la pared; es decir, con pocas opciones para sobrevivir de la vocación agrícola. Frente a esta situación encuentran dos tipos de flexibilidad laboral, una donde los agricultores familiares se sienten obligados a reducir su labor a medio tiempo o algunas veces como pasatiempo, con lo que se disminuye la conexión de la familia con la producción agrícola. En el segundo escenario laboral, las familias logran mantener su identidad de agricultores familiares trabajando a tiempo completo. Sin embargo, para poder hacerlo se incorporan a nuevos tipos de prácticas, como al turismo y la educación, con lo que se fomenta la cooperación de todos los miembros de la familia, más allá del género o grupo etario, opción que requiere una expansión de la labor familiar fuera de la agricultura.

\section{ANTECEDENTES}

A pesar de las variaciones del desarrollo agrícola en distintas zonas del país, por ejemplo, la producción de banano en la Costa Atlántica, la producción agrícola se presentaba en la mayor parte de las zonas del valle central. El siglo XIX estuvo marcado por la creación de un significativo sector de pequeños y medianos productores de café que lograron acceso y apropiación de la tierra (Fernández, 1984; Mora-Alfaro, 1989; Paige, 1997). Según establece Fernández (1989), la estructura de la propiedad y el uso del suelo concentró a los grandes productores en la zona central y a los pequeños productores en zonas periféricas, al establecer una frontera agrícola que permitió la apropiación significativa de parcelas de tierra por parte de campesinos en el siglo Xx. Este hecho histórico marca un fuerte contraste con El Salvador y Guatemala, sus vecinos centroamericanos, donde las élites cafetaleras acapararon la tierra y la producción agrícola tanto en zonas centrales como periféricas (Paige, 1997).
Tomando en cuenta un sector costarricense de pequeños y medianos productores con acceso directo a la tierra en la zona central, los procesos macro-estructurales que orientan la agricultura distinguen dos periodos temporales durante la segunda mitad del siglo xx. En un primer periodo, los cambios provocados por la revolución verde de la década de los 50 , cuando los agricultores de Costa Rica adoptaron modelos de intensidad de los cultivos, especialmente en la producción de café en la región del valle central, con lo cual ingresaron o expandieron su participación en mercados internacionales (Samper, 2010). De acuerdo a Mora-Alfaro (1989), desde 1948 hasta 1978 se consolidó la modernización del agro en Costa Rica, provocando la división de tres sectores de productores agrarios, un sector de unidades productivas terratenientes que se transformó en empresas capitalistas agrarias, un segundo grupo que integró a algunos productores familiares que destinaban su producto al mercado exterior $y$ un amplio tercer sector de productores, típicamente de escala pequeña o mediana, dedicados al mercado interior y la economía de subsistencia (Mora-Alfaro, 1989). Estos sectores se consolidaron como resultado de la presión por el acceso a la tierra y las políticas de redistribución de tierras, entre estas, la llamada Programa de dotación de tierras del IDA, un programa insigne de dotación de tierras que distribuyó 663889 hectáreas, beneficiando directamente a 32961 familias campesinas sin tierras, lo cual se dio entre 1963 hasta 1986, según lo expuesto por Walter Robinson Davis, gerente del Instituto de Desarrollo Agrario en 1987 (Robinson-Davis, 1987).

En el segundo periodo, a partir de 1980, se acentúa la estrategia aperturista donde el Estado ofreció estímulos a la producción dirigida al mercado exterior, mientras abandonaba lentamente los estímulos dirigidos al mercado interno (Mora, 1989). De acuerdo con Morales y Segura (2014), desde la década de los 90, ha existido una rápida reducción de la extensión territorial agropecuaria de pequeños productores y una concentración de tierras en manos de grandes propietarios. Como se evidencia, el $20 \%$ de las fincas grandes a nivel nacional 
constituían el $80 \%$ de la superficie, dejando una extensión territorial de apenas el $20 \%$ para pequeños productores (Morales y Segura, 2014). En este proceso se da la inserción completa a los mercados internacionales de productos alimentarios a través de políticas neoliberales que propiciaron la firma de los tratados de libre comercio en las décadas de los 90 y 2000 (Faure y Samper, 2004). Según el Ministerio de Comercio Exterior de Costa Rica, se encuentran vigentes 15 acuerdos de libre comercio, entre ellos, el tratado de Libre Comercio entre Estados Unidos, Centroamérica y República Dominicana, por sus siglas en ingles CAFTA, suscrito en el año 2004 y enviado a referéndum en el año 2007, donde fue ratificado, para entrar en vigencia en 2009 en Costa Rica (Pacheco, 2004; Redacción Universidad, 2017). Las narrativas de desempeño del CAFTA muestran comportamientos antagónicos, uno de éxito y otro de fracaso, que resultan en estudios no conclusivos, pues como se indica en el Informe del Estado de la Nación de Costa Rica a 10 años del CAFTA: "Desde su formulación se han presentado argumentos a favor y en contra de los efectos de dicho acuerdo. La literatura es extensa y variada, desde artículos de opinión hasta libros y artículos académicos que analizan el tema" (Programa Estado de la Nación, 2017).

En efecto, la narrativa que acentúa los beneficios de los acuerdos comerciales proyectan ampliamente tendencias positivas para la agricultura costarricense, al enfatizar el aumento de las exportaciones, la inversión extranjera y el éxito de empresas nacionales ante la competencia de transnacionales (Programa Estado de la Nación, 2017; Redacción Universidad, 2017). En esta línea narrativa, específicamente, algunos economistas consideran al libre comercio en Costa Rica como un éxito total (Clark, 1997; Gingrich y Garber, 2010). Sin embargo, esta perspectiva ignora las consecuencias de la estructura productiva históricamente erigida desde la pequeña producción, donde la agricultura familiar se pone en desventaja frente a las empresas transnacionales (Martínez Franzoni y Castro, 2004). Además, ignora la complejidad de las transiciones agrícolas por los procesos de nivel micro, así como, la agencia propia de los agricultores y su reacción a estas condiciones, ya sea dentro de la organización comunitaria $o$, como se interesa en este texto, la organización del hogar como unidad productiva. Especialmente, desconoce las decisiones concretas que enfrentan los actores sociales que participan y desafían las condiciones cotidianas de una agricultura integrada verticalmente. Además, es importante reconocer que, en este contexto desafiante, las mujeres que dedican su vida al agro han enfrentado otro reto extra, el acceso limitado a la propiedad de la tierra, lo cual generó una brecha de género en la posibilidad de apropiación de la tierra ya sea por compra, herencia, beneficio o subsidio (Deere $y$ Leon, 2003).

Algunos estudios como los presentados por Fernández (1984 y 1989), así como el estudio antropológico de Edelman (1999), han demostrado que la adopción de los monocultivos del café en la década de los 70 en Costa Rica se caracterizaron por cambios radicales a nivel social $y$, por lo tanto, se enfrentaron con movimientos sociales rurales fuertes en las décadas de los 80 y 90 (Edelman, 1999). En otras áreas del país, por ejemplo, en la región de los Santos, la migración al exterior sirvió como una válvula de escape para los caficultores, quienes estaban enfrentándose a la restructuración capitalista neoliberal (Caamaño, 2010; Samper, 2010). También, en el norte del país, Faure y Samper (2004), identificaron específicamente cinco estrategias adoptadas por los agricultores frente a la liberalización del comercio: la especialización de producción para la exportación, la modernización de producción para tener mayores ventajas en los mercados nacionales, la adopción o renovación de modos de producción alternativos, la permanencia de antiguos sistemas de producción y la postura defensiva de reducir las operaciones a lo mínimo en espera de cambios futuros del mercado agropecuario.

La zona del Valle Central de Costa Rica se convirtió en el centro de referencia espacial de desarrollo agrícola de un sector influyente de productores familiares a pequeña escala (Fernández, 1989). De hecho, el cooperativismo se impulsó en esta zona precisamente por el auge del café durante los años 50 y se mantiene como un 
modelo de organización agraria fuerte hasta la actualidad (Mora-Alfaro, 1987; Rojas, 1989). En esta zona, la formación de organizaciones campesinas y cooperativas han servido de fuerte contrapeso en coyunturas que propician cambios en la política agraria, por ejemplo, durante la llamada agricultura del cambio y la campaña del Tratado de Libre Comercio (TLC) en la década de los 2000. Sin embargo, frente a las presiones neoliberales del libre comercio y la reducción de los costos de producción, se depende cada vez más de la mano de obra temporal y extranjera, sobre todo de migrantes nicaragüenses, una situación que tiende a disminuir la organización y el alcance del poder colectivo de los agricultores (Voorend $y$ Robles, 2011).

Asimismo, la unidad familiar como motor de los procesos organizacionales agrícolas permite fortalecer la concientización colectiva que actualmente valora más la producción local y sostenible. Con esta visión de mercado surgen nuevas alianzas, tipo "Fair Trade" — de comercio justo- o "Rainforest Alliance", la cual supuestamente certifica los productos para ajustarlos a las exigencias del mercado global y mejorar la sostenibilidad de los sistemas productivos o el rendimiento del porcentaje de la venta que reciben los productores. Así, se supone que los productores del Valle Central pueden ubicarse en una posición favorable que les permita aprovechar esta nueva demanda económica de parte del consumidor, tal como lo han hecho las cooperativas productoras de café y azúcar integradas a este mercado (Babin, 2015; Sick, 2008). El consumidor actual muestra una fuerte tendencia a favorecer a la pequeña producción, realizada en unidades familiares, y se posiciona en contra de la producción masiva, que efectivamente organiza las relaciones de producción agrícola mundial. Solo hay que ver una caja de té (o una barra de chocolate o una bolsa de café en grano), en su empaque el cual incluye un párrafo sobre la historia de la familia, así como sus nombres y edades, indicando quienes serán beneficiados por la venta del producto. Lo interesante es que al igual que la venta en nicho de productos orgánicos o producidos por métodos sostenibles, la narrativa de una familia siempre se plantea como el centro de la historia de la producción del alimento (Carlson, 2008).

La familia como concepto central y clave se caracteriza nuevamente como un componente único en la modernidad agrícola. En este artículo, se plantea una exploración concreta de la organización familiar de las fincas en la región occidental del Valle Central de Costa Rica. La pregunta específica de exploración se puede definir de la siguiente manera: ¿cómo se posicionan los agricultores familiares, en términos macro, en este esquema de la agricultura que ha pasado de (a) los monocultivos y la intensidad de producción a (b) los mercados internacionales por medio de los tratados de comercio libre a (c) la apertura que representa la venta a consumidores que valorizan cada día más la historia y proceso de producción tanto como al mismo producto? Este estudio argumenta que existe interés de parte de los miembros de las familias con herencia agraria en continuar con la labor agrícola, pero las adaptaciones que implementan para poder hacerlo introducen cambios que debilitan al agricultor familiar que en el pasado ha sido el elemento central de la organización político-económica en Costa Rica.

\section{LA CONCEPTUALIZACIÓN DEL AGRICULTOR FAMILIAR}

Como unidad de investigación interesa no un sector agrícola específico, ni los que se dedican a un tipo de cultivo, sino los "agricultores familiares en conjunto". Aunque existen varias definiciones, en este trabajo se entiende agricultores familiares como la "unidad doméstica de producción y consumo", que involucra relaciones sociales para realizar la fuerza laboral, así como relaciones con el medio ambiente $y$ culturales, que son "territorialmente diversas y dinámicas", con variaciones locales y regionales en términos de proyecto del Estado (Samper, 2016, pp. 10-11). De esta manera, la generación de una política de agricultura familiar ocurre de forma conjunta con la evidente reducción de la agricultura de subsistencia y la entrada de los pequeños productores a los mercados internacionales (Sabourin et al., 2015). 
De acuerdo con el antropólogo Robert Netting (1993), los agricultores familiares "smallholder, householder" se definen como "farmers who practice intensive, permanent, diversified agriculture on relatively small farms in areas of dense population"2 (Netting, 1993, p.2). Así, los agricultores ejercen procesos de expansión o disminución de operaciones y tipos de productos dependiendo de las condiciones donde se encuentran y las relaciones que forman con la población a su alrededor. Bajo esta conceptualización, una unidad familiar puede entrar o salir de un sector de cultivo según los contextos de producción y del mercado. De aquí en adelante, se utiliza el término "pequeños agricultores familiares" para captar mejor la definición de Netting y para caracterizar las 32 fincas que forman parte de este estudio, con productores radicados en algunas zonas estratégicas del Valle Central de Costa Rica.

\section{METODOLOGÍA}

Este estudio se realizó de julio a diciembre de 2017, por medio de dos técnicas cualitativas: (a) trabajo de campo realizado en una estancia académica en Atenas, un cantón con identidad sumamente agrícola, incluyendo la participación y la observación de eventos agrícolas organizados en varias partes de esa cantón y (b) entrevistas a 56 agricultores familiares quienes laboraron en 32 fincas ubicadas en la provincia de Alajuela, cantones de Atenas, Palmares, San Ramón, Grecia y Zarcero, así como el cantón de Turrialba en la provincia de Cartago. La investigación se enfocó principalmente en el cantón de Atenas y la provincia de Alajuela por sus características de ser una zona de "interconexión rural-urbana" (ruralurban interface). La literatura sugiere que los productores de estas zonas pueden tener mayores éxitos por la cercanía de los mercados y la posibilidad del comercio directo entre el agricultor y el consumidor (Inwood y Sharp, 2012). Las entrevistas realizadas en Turrialba,

$2 \quad$ Traducción: "los agricultores que ejercen la agricultura intensiva, permanente $y$ diversificada en fincas pequeñas y en las áreas con densidad poblacional". donde mayoritariamente se dedicaba al cultivo de azúcar y la producción de leche para la elaboración de queso, se utilizaron para comparar la situación productiva con la provincia de Alajuela, donde los agricultores familiares se dedicaban mayormente al cultivo del café, cítricos y hortalizas. Además, se incluyeron familias productoras de larga trayectoria y las que recientemente se integraban a la vocación agrícola.

\section{LA SELECCIÓN DEL SITIO PARA EL TRABAJO DE CAMPO}

Se determinó que el cantón de Atenas sería un sitio ideal que se caracteriza como zona de "interconexión urbano-rural". Aunque, anteriormente, Atenas se consideraba como un pueblo sumamente agrícola, durante los últimos 20 años se ha caracterizado como una zona en transición localizada relativamente cerca de la capital, San José. Por lo tanto, los agricultores de Atenas tienen acceso al mercado de una población dispersa alrededor de la ciudad, una de las más dinámica del país. Para los productores eso implica acceso a mercados importantes, población educada y con interés de promocionar comida producida a nivel local con métodos sostenibles, lo que puede beneficiar al pequeño productor. Además, los agricultores cuentan con la actividad turística, especialmente internacional, que resulta ser una oportunidad clave para la agricultura familiar (Vindas, 2020).

Se utilizaron métodos etnográficos para comprender los elementos importantes del contexto en el cual operaban los agricultores familiares. Por lo tanto, se realizaron entrevistas formales a 14 personas que trabajan oficialmente con agricultores, desde agentes del gobierno, representantes de las cooperativas, sindicatos de agricultores y de oNG. Se visitó de forma regular los sitios donde los pequeños productores vendían productos localmente en el mercado central y también en la tienda de la cooperativa. Además, se realizaron 18 días de visita a la feria del agricultor en Atenas, Grecia, Ciudad Colón y Turrialba. Adicionalmente, se asistió a varios eventos de características agrícolas de la zona, incluyendo la subasta del progreso, dos subastas de beneficio organizados por las iglesias, un 
rodeo, el tope nacional de San José y dos desfiles en Atenas, donde en todos ellos se observaba la influencia significante de los productos para la identidad del cantón. Se realizaron varias entrevistas improvisadas durante los 6 meses de estadía, así como conversaciones informales con pobladores atenienses sobre los cambios agrícolas en la zona.

\section{LAS ENTREVISTAS FORMALES CON AGRICULTORES FAMILIARES}

Para investigar la manera en que los pequeños agricultores familiares se posicionaban frente al contexto de la exclusión debido a la liberalización agraria y la posible apertura de las nuevas valorizaciones relacionadas a la producción de la comida, se entrevistó de manera formal a 56 miembros de familias productoras procedentes de 32 fincas. Se identificó a los participantes del estudio a través de las visitas a las ferias del agricultor y también por recomendaciones de contactos que se hicieron durante el trabajo de campo con residentes de Atenas, con oficiales que trabajan formalmente con los agricultores y con contactos personales. La mayoría de las entrevistas realizadas en las fincas comprendieron jornadas de observación participante $y$ múltiples conversaciones con miembros de las familias. Concretamente, 16 de las 32 entrevistas incluyeron un tour en la finca. Asimismo, en 14 de las 32 fincas se tuvo contacto con múltiples agricultores, y en 20 de las 32 fincas se recibieron las perspectivas de más de una persona de la familia. Además, de las 32 fincas, 22 se caracterizaban como fincas con larga tradición generacional y 10 como principiantes.

Para poder investigar si las experiencias de los productores en el cantón de Atenas, fueron específicas a las condiciones de la zona 0 más bien son representativas de otras regiones del Valle Central, se identificaron a algunos agricultores ubicados en Turrialba, Palmares, Grecia, San Ramón y Zarcero. Las familias fuera de Atenas se dedicaban a la agricultura alternativa, sostenible u orgánica $y$, en el caso de Turrialba, se dedicaban a producir lácteos para el mercado nacional y la producción de caña para el mercado internacional. De las 32 fincas,
19 se encontraban en Atenas, 2 en Grecia, 1 en Palmares, 8 en los alrededores de Turrialba y 2 en Zarcero.

Las entrevistas fueron grabadas y en estas se cubrieron los siguiente temas: un resumen de las operaciones actuales de la finca (qué se produce), la historia de la finca (cómo se consiguió la finca, qué transiciones han pasado), quienes trabajan en la finca, el mercadeo, la economía de la finca, rasgos individuales (dónde se creció, experiencia laboral previa, experiencia educacional), las rutinas diarias (distribución de trabajo y quehaceres), historia de trabajo asalariado fuera de la finca, crianza de los niños (en caso de ser aplicable), comentarios sobre los apoyos con los cuales cuentan, los reglamentos que manejan y su visión para el futuro de la finca. Mientras que la primera autora, quien previamente realizó trabajo de campo con agricultores en Estados Unidos, recolectó todos los datos, incluyendo el trabajo de campo y las entrevistas; la segunda autora, quien posee experiencia trabajando con mujeres agrícolas en El Salvador y Nicaragua, aportó a la estructura, lógica, contextualización histórica $y$ análisis.

\section{PLAN DE ANÁLISIS}

Los datos recolectados en las diversas zonas de Costa Rica forman parte de un amplio estudio de familias agricultoras. Durante los tres años anteriores, la primera autora realizó entrevistas a 76 miembros de 50 familias que se pueden definir también como pequeños agricultores familiares en el Estado de Nueva York (Dreby y Carr, 2019; Dreby et al., 2017). La muestra en Nueva York logró incluir tanto las perspectivas de las fincas históricas (22 de las 50 familias) como las de familias con proyectos de fincas nuevas (28 de las 50 familias) (Inwood et. al., 2013). De esta forma, el propósito del trabajo de campo desarrollado en Costa Rica fue de replicar analíticamente, de la mejor manera posible, algunos puntos claves de la investigación más amplia realizada en Nueva York, adaptándolo a la realidad $y$ al escenario del país. Por este motivo, se incluyeron varios tipos de productores, incluyendo familias con larga trayectoria generacional $y$ las que recientemente se integraban, 
dentro de una zona de interconexión ruralurbana en el país centroamericano. Es decir, el plan analítico se diseñó desde un principio con el objetivo de elaborar un análisis comparativo.

Por lo tanto, se utilizó un enfoque de análisis teórico que involucra la codificación abierta de datos de entrevistas combinada con codificación específica, según los temas identificados durante el proceso de codificación abierta. Basado en el análisis de datos recolectados previamente, se decidió enfocar a la familia como unidad de análisis. Así, el criterio de participación era que se consideraran, ahora o en algunos casos anteriormente, agricultores de pequeña o mediana escala, que trabajaban con base a la labor familiar en la venta de diferentes tipos de productos. En Costa Rica, la muestra incluyó a 7 productores orgánicos, 2 de hidroponía, 2 que se dedican a la producción de semillas, 5 que se dedican a la crianza de abejas, 12 que producen café, 8 con ganado, 4 que tienen lecherías, 6 que se dedican al cítrico, 4 que siembran caña y 6 que se enfocan sobre todo en varios tipos de hortalizas.

El primer paso de análisis fue considerar si existían variaciones dentro de la muestra en adaptaciones según el tipo del cultivo. Así, se identificó que es mejor no enfocarse en los tipos de productores, en 28 de las 32 fincas, los agricultores se dedican o se han dedicado a varios tipos de cultivos. Por ejemplo, una familia que producía anteriormente café y se identificaba todavía como caficultora, debido a los precios bajos en el mercado la producción de café se limitó al consumo familiar. Otro escenario, ante esta situación, es que la producción se diversificaba, extendiéndola a árboles cítricos dirigidos hacia la venta de limones; anteriormente usado exclusivamente para el consumo propio. Además, como al hijo de la familia que le gusta más trabajar en el campo y no le interesan ninguno de estos dos cultivos, sino más bien el ganado, con lo que ha decido mantener en la finca 4 a 6 vacas para la crianza $y$ venta de carne. De este modo, enfocarse en un solo tipo de cultivo atenúa los procesos de cambio $y$ adaptación. Una limitación del estudio es que no se hicieron entrevistas con los que dejaron la vida agrícola, así que los testimonios analizados son de los que decidieron adaptarse $y$ seguir produciendo, aunque sea a medio tiempo con producción mínima a pesar de las dificultades estructurales que enfrentaban. Sin embargo, el tema de la adaptación es sumamente importante, $y$ limitarse en solo un tipo de productor introduce cierto sesgo a la muestra, esto se evita poniendo la unidad familiar como centro de la investigación.

El segundo paso de análisis fue considerar más detalladamente qué tipos de adaptaciones utilizaron los agricultores familiares que forman parte de la muestra. Así, se evidencia que las familias se encuentran con una bifurcación que las obliga a tomar una de dos salidas. Por un lado, un camino de expulsión de la práctica agrícola familiar tradicional, donde sus miembros ven imposibilitada la vocación del trabajo agrícola a tiempo completo (aquí el proyecto de finca se topa contra una pared metafórica). En este contexto, el trabajo en la finca se convierte de forma obligatoria en un trabajo de medio tiempo, pasatiempo o una vocación única para la generación jubilada $y$ no una obra hecha por la familia completa. Por otro lado, el camino alternativo es adaptarse a un mercado que implementa nuevas formas de valor agregado para mantener los procesos productivos familiares, al introducir en la finca procesos transformadores que fundamentalmente cambian al proyecto agro-familiar (aquí el proyecto de finca se enfrenta a la espada de forma metafórica).

Como consecuencia de esta compleja realidad agrícola, el productor se posiciona ante una pared atrás y una espada al frente, sin poder escapar. Por lo tanto, para poder mantenerse económicamente solvente como familia agrícola la opción es posicionarse estratégicamente frente a la realidad cambiante que representa la espada, insertándose en los nuevos mercados de forma novedosa, irónicamente en resistencia a la globalización, al ofrecer a turistas la experiencia de una finca de familia como parte de la venta de su labor agrícola. En otras palabras, la tendencia se vuelve no solo hacia la producción, sino hacia la habilidad de trascender la producción agropecuaria e integrar a los miembros de las familias en nuevos quehaceres 
como turismo, educación, venta y producción. Es decir, el agricultor responde al mercado global integrando estrategias propias de este mercado dentro de sus estrategias familiares agrícolas, pero no como mecanismos de adaptación sino de resistencia (Rodriguez-Sperat et al, 2015). Teóricamente, estas dos estrategias de dejar de depender económicamente en la producción agrícola o de trascender la producción agropecuaria, demuestran la flexibilidad de la familia como unidad de organización económica; empíricamente, explican las presiones que enfrentan, los desafíos que sienten y los tipos de ajustes que son necesarios para la sobrevivencia del pequeño agricultor familiar en la zona del Valle Central de Costa Rica.

\section{LA PARED: LA SALIDA DE LA AGRICULTURA COMO VOCACION FAMILIAR}

Durante una semana, la primera autora asistió con ansías al gran rodeo del 2 de diciembre, tal vez por el hecho de que, un vecino le avisó del evento un mes antes: "Usted debe ir, es un evento bien bonito, muy lindo", "si no le han invitado ya yo le invito a usted que vaya" (conversación informal, comunicación personal, noviembre de 2017). Después, vio un letrero que anunciaba el evento, sería en el balneario no tan lejos de la casa. Posteriormente, dos días antes, empezaron a perifonear desde un carro que rodeaba las calles anunciando el espectacular rodeo que daría inicio a las 7 de la noche aquel sábado.

Llegó el sábado y su bebé se durmió tarde, fue hasta las 8:30 que salió corriendo con su hijo Dylan de 11 años como acompañante, dejando al hijo de 15 años cuidando de su hermanito menor. Caminó apurada, no quería perder el evento... “¿Dónde está el gran rodeo?” se preguntó, confundida, hasta que Dylan se cansó de la incertidumbre y le preguntó a un señor que apareció por allí — parecía un empleado del parqueo donde estaba el rodeo-.

"A la vuelta", explicó, y seguro que sí, detrás de la piscina y el bar, subiendo más al cerro, ahí encontraron una arena no tan pequeña donde estaba el evento. Había un presentador, música y tal vez fue simplemente anomalía que aquella noche el sonido no llegara afuera. Después, tomaron asientos en las gradas de concreto alrededor de la arena y al mirar a los lados se dio cuenta que estaba a menos de un cuarto de su capacidad total, interpretó el silencio y la confusión de aquella noche como algo diferente. A pesar de los anuncios frecuentes que había escuchado, más que por cualquier otro evento durante los seis meses de estancia en el pueblo, sorpresivamente el evento no fue muy popular en Atenas. El rodeo fue bonito pero tan solo para unos pocos, un selecto grupo, que llegó a ver el toro pronosticado como campeón ese año o el joven jinete con récord impecable. Este rodeo fue un recuerdo de lo que fue Atenas, $y$ la identidad principal del pueblo, pero no de lo que es hoy.

Así se encontraba la situación de la agricultura en Atenas. Como un señor de 35 años exclamó al principio de la entrevista, "Atenas era un pueblo agricultor. Era. Ya no es" (entrevistado 19, comunicación personal, septiembre de 2017). Él había crecido en la finca de su papá donde todavía se produce café y se dedicó a la siembra de tomate en este terreno hasta unos dos años atrás, cuando decidió tomar un trabajo fuera porque sencillamente no podía seguir en la vocación y mantener a sus dos hijos en edad escolar. Otro señor y su hermano tienen una historia similar: el papá de estos era uno de los organizadores originales de la cooperativa del pueblo y mantenía a su familia con la venta de varios productos agrícolas, aparte del café, que exportaba por medio de la cooperativa. Ambos hermanos dejaron de estudiar a los 12 o 13 años, no veían necesidad de seguir estudiando porque pensaban trabajar con el papá en la finca. Fue una labor que realizaron hasta 10 años atrás cuando se dieron cuenta que ya no podían sostener a sus familias con este trabajo. El hermano mayor entró a la policía y el menor encontró un trabajo en la compañía de electricidad. "Como amo al trabajo de la tierra," comentó el hermano menor con aires de nostalgia. "Me encanta pasar el día afuera, en el aire puro. Si yo podía hacerlo, uf, estaría yo feliz." (entrevistado 3, comunicación personal, agosto de 2017).

Muchos de los entrevistados comentaron, como los dos hermanos, de la pérdida de la 
agricultura como forma de vida. Algunos lo lamentaban, como el taxista que al enterarse de la investigación dijo lo siguiente: "yo sé mucho de eso, pero no se puede, ya no se puede. $\mathrm{Mi}$ papá tiene finca, tenía finca, y le llevo a usted a hablar con él, si gusta, pero ya no se puede si cuesta a uno tanto para criar al animal y a la hora de la venta solo le pagan máximo 1300 colones al kilo. No, ya no se puede en eso" (taxista, comunicación personal, septiembre de 2017). Otros opinaban que estaba mejor que los hijos estudiaran porque el trabajo de campo es muy duro. "Yo digo que es bueno que mi hijo se prepare" (entrevistado 19, comunicación personal, septiembre de 2017), ya que, según él, el precio de la tierra actualmente es demasiado alto.

La explicación de la pérdida agrícola, según los entrevistados, se debía a varias razones. Algunos lo consideran como resultado de la brecha generacional, marcada por el hecho que los hijos estudian y "ya no quieren trabajar la tierra" o puede ser que ya no saben trabajar bien; comentó un caficultor: "por las leyes que ya no pueden trabajar los niños. Si no lo hacen desde chiquito ya no saben cómo trabajar bien." (entrevistado 8, comunicación personal, agosto de 2017). Más de uno comentó que: "solo los extranjeros [nicaragüenses] saben trabajar la tierra." (entrevistado 29, comunicación personal, noviembre de 2017) (ver Voorend y Robles, 2011). Sin embargo, aunque en muchos casos se indicaba que los hijos no les interesaban las fincas de los papás, también estaban los que sí querían trabajar en el campo. Por ejemplo, en una conversación en noviembre de 2017, un vecino de 17 años que terminó el último año del liceo ese diciembre. Él quería ser veterinario porque le encanta trabajar en el campo y con el ganado. El problema, explicó, es que no puede hacerse la vida en el campo como había hecho su papá. Así que no es tanto que no existen las ganas; más bien, para estos agricultores y la nueva generación, es que la economía de la finca es cada vez más difícil. Las ganas de trabajar en el campo existen, los medios para hacerlo como vocación principal son los que faltan.
Los jóvenes criados en fincas en otros cantones tenían experiencias muy parecidas a los de Atenas. En una conversación informal en octubre de 2017, un señor de 38 años que vivía en las afueras de Turrialba, por ejemplo, empezó a trabajar en la agricultura a los 12 años junto con su hermano, cuando se encargó de la finca de la familia mientras que su papá trabajaba por un salario afuera. De allí, trabajó un tiempo para un pequeño productor de caña, luego en una lechería y después para una compañía de azúcar orgánica que se estableció en el pueblo. Posterior a un accidente laboral, regresó a estudiar en la universidad y actualmente trabaja cuidando una finca. Lo interesante es que él recibirá un terreno como herencia, pero, según expresó, conociendo el mundo agrícola no piensa levantar su propia finca.

¿Por qué antes se podía vivir de una finca $y$ hoy en día no? la pregunta es compleja. Los entrevistados tienen una explicación concreta y práctica. Ahora los costos para producir son muchos más que antes y la utilidad del producto es mucho menos, reduciendo los márgenes económicos generados por los productores (Renting et al., 2003). Claro, esto depende mucho del producto, pero es la tendencia en la que concordaron todos los productores entrevistados. Primero, a pesar de las diferencias del producto, los agricultores gastan mucho más que antes en fertilizantes y abonos. Los productores de mayor edad recuerdan que años atrás la tierra en Atenas era mucho más rica que ahora. "Antes la levantaba un puño y estaba negra y llena de lombrices" recordó una señora de más que 80 años que vivía de la agricultura toda su vida. "Antes no se echaba químicos y que bonito se producía." (entrevistado 10, comunicación personal, septiembre de 2017). En la perspectiva de estos productores convencionales, las plantas no producen si no se les echan químicos. Específicamente, los productores de café han sufrido muchos problemas de plagas que requiere más aplicación de químicos. Un caficultor comentó: "antes se echaba 2 veces al año, este año creo que ya voy por más de 5 aplicaciones." (entrevistado 29, comunicación personal, noviembre de 2017). 
Resulta interesante mencionar que la mayoría de los entrevistados mencionaron al cambio climático como factor principal que contribuye al aumento de los costos de producción. Relacionaron directamente la proliferación de las plagas, por ejemplo, al cambio climático que modifica drásticamente las zonas micro climáticas de la región, así como a los cambios de hábitat de las especies. Asimismo, cambios en el clima sobre todo en la cantidad $y$ previsibilidad de las lluvias.

Otro cambio que puede afectar la economía de la finca es que ahora los productores suelen comprar las semillas, o las plantas, en vez de utilizar las semillas que se producen en la misma finca. Un señor que produce tomate, por ejemplo, recuerda que con su papá sembraban otro tipo de tomate criollo y tomaban las semillas de la cosecha anterior. Ahora, se compra las plantas pequeñas en vez de sembrar las semillas porque los productos híbridos no permiten utilizar las semillas de cosechas anteriores (entrevistado 11, comunicación personal, septiembre de 2017). Un caficultor recuerda que de joven él hacia su propia plantación de café. De hecho, así compró su casa cuando se casó, vendiendo todo su cultivo. Ahora, como es mayor de edad $y$ no puede hacer el trabajo solo, le sale más económico comprarlas que pagar a un peón el tiempo de siembra y cuido de pequeñas plantaciones (entrevistado 29, comunicación personal, noviembre de 2017).

Para algunos productores comprar afuera es económicamente más beneficioso porque se gasta menos en la mano de obra o porque así se pueden obtener plantaciones más resistentes. El problema es que, a largo plazo, se crea dependencia la cual genera más costos de producción que no se recuperan con la venta del producto. Ciertamente, los cambios de sistemas de producción son complejos, en parte debido a mejoras tecnológicas que han causado cambios estructurales en producción. Aun así, desde la perspectiva del agricultor familiar, la economía de la finca se complica como resultado de la dependencia de nuevos sistemas de producción y la impotencia de solucionar estas complicaciones a través de la labor familiar.
Con el aumento de los costos en la finca, se menciona la variación de precios en la venta, los cuales también se alteran según el producto. En el caso específico del precio del café, por ejemplo, se ha mantenido a la baja y esa inestabilidad del precio es la causa de los problemas de los caficultores entrevistados (Hartley, 2010). Esta problemática suele pasar también con otros productos. En una subasta, una productora vendió 18 terneras, por lo cual estaba contenta sacando las cuentas con su empleado a la salida del evento, pero al cuestionarla "¿y cómo compara con el costo de crecerlos?" su respuesta fue enfática "Oh, no, eso no me preguntes, por favor, para ponerme de malas. Déjame disfrutar el momento" (entrevistado 30, comunicación personal, noviembre de 2017), explicando que seguramente no recuperaría lo que había gastado, nunca lo hacía, aunque la venta de ese día fue mejor de lo normal.

Para la mayoría de los productores entrevistados, el costo de producción no se compensa con la venta de los productos. Así que para seguir en una vocación que realmente aman, tienen que encontrar otras fuentes de trabajo alternativos o generar dinero de otra manera para invertir en la finca. Se evidencia, por tanto, la pérdida de la agricultura "como algo que fue, y que ya no es como antes." (entrevistado 19, comunicación personal, septiembre de 2017). En este contexto, los agricultores familiares tratan de adaptarse al mercado moderno creando estrategias novedosas que posibilitan alternativas de desarrollo rural desde la intervención local (Paz et al., 2011).

\section{LA CONTINUACIÓN DE LA AGRICULTURA COMO IDENTIDAD FAMILIAR}

La gran mayoría de entrevistados se identificaron con valores asociados a una vida de campo, a saber, trabajar, la autosuficiencia, la humildad $y$ hasta la igualdad social. Una señora que heredó la finca de café de su papá describió su juventud en el campo como ejemplo de igualdad social, un vínculo que a su juicio se está perdiendo en Costa Rica con la llegada del consumismo y la preocupación entre las nuevas generaciones del materialismo. Recordaba que de niña pasaba los días en la finca junto con 
las hijas del peón que empleaba su papá. "Me acuerdo que caminábamos todos juntos a la escuela; ellas subían en las botas y dejaban los zapatos limpios en mi casa. Se cambiaban de zapato y íbamos a la escuela." (entrevistada 17, comunicación personal, septiembre de 2017). Eran amigas fieles, o así lo recordaba la entrevistada, su unión se debía al trabajo de campo, la amistad y el sentido de igualdad compartido. Las dos ayudaban a los papás con las tareas del campo y juntas jugaban afuera en la naturaleza todo el día. "Creo que este contacto entre las clases sociales se está perdiendo ahora." (entrevistada 17, comunicación personal, septiembre de 2017).

Aunque es fácil imaginar que la nostalgia colorea las memorias positivamente, otro agricultor también compartió memorias parecidas, sobre crecer junto a los hijos del patrón de su mamá en la finca. Él dedicó su vida al campo, su camino de jornalero a ser propietario fue por adquisición personal no por herencia y ya como adulto considera a los hijos del patrón como colegas: participan juntos en la cooperativa y el sindicato (entrevistado 7, comunicación personal, agosto de 2017). De tal manera, el valor más repetido entre los entrevistados es el de la familia.

Por supuesto, existen diferencias que complejizan la organización de trabajo dentro de la familia. Se notan dos tipos de prácticas laborales familiares entre las parejas, una en la cual el hombre se dedicaba más al campo y la mujer a la casa, otra donde ambos trabajaban activamente en la labor agrícola. En un caso, por ejemplo, un señor mayor mencionó que la finca era de él y su esposa, "era un trabajo de los dos". Pero ella se dedicaba a las labores domésticas. "Bueno, ella más se dedica a la casa", explicó, "pero todas las decisiones siempre las hemos hechos juntos, ella y yo. Todo esto es de los dos." (entrevistado 29, comunicación personal, noviembre de 2017). En otro caso, el esposo $y$ la esposa se dedicaban al negocio familiar $y$ labor agrícola. Ella decía: "Me encanta trabajar al aire libre, tengo que estar activa, no me conformo con estar sentada todo el día." (entrevistada 8, comunicación personal, septiembre de 2017). Ella se encuentra afuera trabajando en las plantas, llevando el producto al mercado $o$ vendiendo en la feria igual que su esposo. A pesar de algunas variaciones (especialmente en lechería), se logra distinguir en las prácticas laborales familiares una división del trabajo entre hombres y mujeres, en la cual las mujeres en las familias se dedicaban más al trabajo de la casa, elaboración de productos de valor agregado (como hacer el queso), administración, publicidad o contabilidad.

Además de las divisiones entre pareja, también se notaba una organización jerárquica y sumamente patriarcal en las fincas, que trasciende lo local y se presenta como una práctica cultural regional en Latinoamérica (Chiappe, 2005; Menjívar, 2010). Por ejemplo, si la entrevistadora hacía el primer contacto con un hijo, normalmente estos la dirigían al papá como referente principal para que diera la entrevista, aun cuando el hijo estaba involucrado en las operaciones de la misma finca. En un caso concreto, el hijo tenía más de 50 años, se encargaba de cuidar a los animales de la finca, pero decidió que su papá de 75 años diera la entrevista (entrevistado 6, comunicación personal, agosto de 2017). En otro caso, un hijo de más de 30 años, quien vendía productos en la feria, indicó que era mejor hablar directamente con su papá "porque es la cabeza de todo", aunque él era el encargado de la operación de más de la mitad de la finca (entrevistado 4, comunicación personal, agosto de 2017). Este tipo de jerarquía generacional trasciende las fronteras de Costa Rica; es una dinámica de poder simbólico común que surge especialmente durante el proceso de transferencia generacional de la finca, donde la generación mayor ejerce un poder simbólico sobre el resto (Conway et al, 2017).

A pesar de que los patrones de organización están muchas veces subordinados a prácticas generacionales $y$ de género dentro de las familias, algunas decisiones tomadas por agricultores familiares representan un reto consciente a lo convencional, familia tras familia declaraban que la finca era exitosa por el trabajo conjunto de todos sus miembros, como vocación familiar y no individual. Así, la idea de la familia y la cooperación entre sus miembros, esta totalmente integrada al proyecto 
de la finca dándole sentido al trabajo. En otras palabras, la familia como unidad da motivación para continuar la vocación de la producción agrícola que se está perdiendo en esta zona de transición, aun cuando económicamente la familia no puede depender completamente de esta. Los agricultores expresaron repetidamente que consideraban la finca y el trabajo agrícola como un vínculo que promueve la unión en la familia, aunque seguramente en muchos casos también resultaba en conflictos, ya sea entre hermanos, parejas, o padres e hijos. Por lo tanto, los valores familiares los consideran sumamente integrados a los beneficios de la agricultura. A pesar de la evidencia de conflictos, como una historia que terminó en divorcio $y$ varios problemas de herencias entre hermanos, las familias hablaban de la agricultura como una vocación que brinda unidad entre la familia.

Tal vez, por esta razón, a pesar de la pérdida de la agricultura como sustento de la economía familiar, los entrevistados aún seguían dedicándose a labores agrícolas y se identificaban de forma identitaria como agricultores. No obstante, de los 32 entrevistados, 20 hablaron de limitaciones económicas tan severas que los obligó a reducir la escala de la producción de la finca y buscaron empleos fuera, 12 de ellos ubicados en el cantón de Atenas. Algunos de los que decidieron convertir la finca en un trabajo de tiempo parcial, mantenían vivo el proyecto de hacerla crecer en algún momento. Un señor, por ejemplo, no veía manera de vivir en la finca de su papá por lo que decidió emigrar a San José donde trabajó como pintor por varios años hasta que extrañó demasiado el campo y regresó a Atenas, donde inició un trabajo formal cuidando los árboles cítricos y gestionando el trabajo de peones temporales en una finca ajena. Él explicó que su plan era invertir en el linaje genético de los terneros que criaba en su propia propiedad, esperando con el tiempo venderlos y que esto rindiera como trabajo adicional (entrevistado 16, comunicación personal, septiembre de 2017). Otros agricultores describían la labor agrícola más como pasatiempo. Por ejemplo, un señor conocido por todos como apicultor, pero cuyo trabajo principal era ser jardinero de una universidad cercana (entrevistado 21, comunicación personal, octubre de 2017). Otro ejemplo a destacar es el caso de Mateo, un conserje que daba mantenimiento a propiedades en renta, quien era propietario de un extenso cafetal. Anteriormente, él vivía del cultivo de café pero lo había tenido que dejar por la inestabilidad económica que producía esta labor. Mateo con diligencia y orgullo ofreció un tour de sus tierras, mostrando las matas de limón que había sembrado y que de vez en cuando le servían para la venta, aunque aseguró que se dedicaba a las plantas más como pasatiempo, por la costumbre (entrevistado 28, comunicación personal, noviembre de 2017). Resulta interesante que todos estos agricultores crecieron con familias agrícolas, eran dueños de tierras productivas, expresaban identidad $y$ vocación agrícola, y coincidían en la afirmación que no había manera de vivir únicamente de la producción agrícola propia, por eso se volvía necesario disminuir sustancialmente el tiempo que dedicaban al trabajo agrícola.

\section{LA ESPADA: LA ENTRADA AL MERCADO FAMILIAR Y CAMBIOS EN LA VOCACION AGRICOLA}

Doce unidades familiares de las 32 entrevistadas, 7 de ellas en Atenas, se dedicaban $100 \%$ a la producción agrícola y sus fincas eran económicamente exitosas, les permitía a las familias dedicarse al trabajo agrícola con proyección a futuro, inclusive, contemplando futuras expansiones. Eso no quiere decir que no enfrentaban dificultades, de hecho, en muchas historias se describieron desafíos parecidos a los presentados en la sección anterior. La diferencia es que, al contrario de enfrentar una situación que les obligara a reducir significativamente las labores en la finca, estas familias apuntaron sus operaciones hacia la expansión y gracias a sus condiciones particulares pudieron establecer una ruta exitosa. De esas 12 unidades familiares, 4 se identificaban como fincas diversificadas; 4 especializadas en productos orgánicos, 1 en hidroponía, 1 en producción de semillas, 2 mantenían crianza de abejas, 2 producían café, 3 tenían vacas para la producción de leche y 5 se enfocaban 
prioritariamente en varios tipos de hortali$\mathrm{zas}^{3}$. De aquí en adelante, se reflexiona en la organización de estas operaciones, contrarias a las que sufrieron reducción o se encontraron sin salida.

Aunque todos los que continúan en la agricultura se caracterizan por tener una gran capacidad de adaptación, de hecho, contraerse es una forma de adaptarse, los que se sentían exitosos demostraban una flexibilidad enorme en las operaciones agrícolas, junto con un poco de suerte en la sincronización de las innovaciones adaptadas para sus productos dentro de una dinámica de mercado cambiante. Para explicar el proceso de adaptación de una familia que se mantuvo en la labor agrícola a tiempo completo, se toma como ejemplo la familia de Néstor.

Néstor es un apicultor que posiblemente estaba en los últimos años de su cuarta década, o tal vez tenía poco más que 40 años. Un hombre robusto, de buena forma, macizo, no delgado. No parecía no querer conversar y presentó inmediatamente a la entrevistadora con su papá, para que fuera él quien explicara los procesos productivos. Pasadas dos horas y media, Néstor regresó para ofrecer un tour y mostrar las cajas de abejas que construye a mano, la cera que reciclan de las colmenas y la máquina que mide la temperatura de la miel. En ese momento, fue fácil reinterpretar la bienvenida tibia dada por Néstor como un gesto de respeto hacia el papá, quién —con más que 80 años- todavía mantiene el rol como agricultor principal de la casa. El señor, demasiado delgado para ser fuerte, tiene todavía la postura recta, un bigote bien recortado y una mirada juvenil. Asimismo, conserva no solo el respeto de sus hijos, sino también del pueblo por ser reconocido como uno de los pioneros en organizar la cooperativa de café del pueblo, la cual todavía existe (las de otros pueblos visitados ya habían cerrado). La cooperativa vende el producto no solo en el pueblo, sino también a lo largo del país. Efectivamente, todavía se observa la maquinaria del beneficio afuera del pueblo y carteles que cuelgan al frente anunciando "Rainforest Alliance"

3 Varias son diversificadas y se dedicaban a más que un tipo de producto o estilo de producción. y otras certificaciones. Curiosamente, Néstor y la familia ya no producen siembras de café. Los procesos de cambio y adaptación de este núcleo familiar agrícola se relatan a continuación.

Don Alfredo (el papá de Néstor), creció en el pueblo, él se acuerda de la llegada del tabaco a la zona, cultivo presentado a su papá y a otros que hasta ese momento vivían en fincas sembrando arroz y otros productos, que cuando sobraban eran vendidos al mercado del pueblo. Para ese señor, el tabaco fue el primer producto de exportación fuera de la zona; todavía se acordaba de cómo le enseñaron a coger las hojas y enrollarlas para la venta. En su etapa de adultojoven, se fue el tabaco y llegó el café, mientras como pasatiempo mantenían abejas y árboles de frutos para el consumo de la casa, donde crio a sus 5 hijos, incluido Néstor. A pesar de los esfuerzos de cooperativismo en los que participaba su papa, Néstor y sus hermanos salieron a buscar trabajo afuera de la finca, precisamente por la inestabilidad del precio de café.

A Néstor le fascinaba la finca y se dedicó a esta a medio tiempo junto con un hermano, quien crio ganado por unos años, al principio como pasatiempo y luego, cuando creció, como trabajo a medio tiempo. Después de participar en un taller sobre las abejas organizado por la agente de extensión del Ministerio de Agricultura y Ganadería, tomó la importante decisión de expandir la producción de miel para la venta, ya que todavía mantenía las colmenas de su papá. Después de unos años, lograron algo de éxito y Néstor decidió dejar de trabajar afuera de la finca. Seguidamente, un hermano mayor también tomo la misma decisión y dejó su trabajo en una gasolinera para dedicarse a la producción de miel. Hoy, los dos hermanos venden el producto a la cooperativa $y$ a otras tiendas locales. El problema para Néstor no es vender el producto, sino tener suficiente producto para completar la demanda; este año la producción bajó $50 \%$, lo que según indicaron se debió a cambios climáticos y ambientales que afectaron sobre todo la salud de las abejas. Se nota que, en esta familia, así como en otras, ha existido cierta flexibilidad en las operaciones de las fincas para adaptarse a los cambios 
del mercado. Tras el paso de 70 años y los cambios generacionales que trajeron consigo, esta familia pasó de la producción de dos tipos de productos (café y tabaco), a la producción de un único producto, la miel, que comercializaban en el mercado regional (entrevistado 6, comunicación personal, agosto de 2017).

Esta historia parece tener características compartidas por otros productores que han logrado mantenerse triunfantes frente a los desafíos presentes en los cambios del mercado agrícola. Otras dos fincas, que disfrutaban de un negocio próspero, se dedicaron a la hidroponía. Mariana y Jorge, por ejemplo, convirtieron las matas de café que heredaron de sus padres en un sistema de hidroponía para lechuga de plataforma. Explicaban que pasaban mucho tiempo educando al público sobre los beneficios de la hidroponía en los climas de Costa Rica, donde se requieren menos químicos para controlar las plagas y mantener los abonos que requieren normalmente las plantas. De hecho, el patio de la casa contaba con un afiche listando los beneficios a la salud y al medio ambiente propiciados por la hidroponía. Aunque igual que Néstor, Mariana y Jorge transformaron el negocio que anteriormente se inclinaba hacia la venta internacional en algo local, también concluyeron que el mercado nacional tenía sus límites y han logrado equilibrar los procesos adaptándose a los cambios del mercado, manteniéndose estable hasta ahora (entrevistado 8, comunicación personal, septiembre de 2017).

Otra historia similar es la de otro productor, nombrado por un agricultor como "uno de los pequeños productores más exitosos del país". A pesar de vivir una niñez en medio de mucha pobreza, como adulto su condición económica cambió porque decidió apostarle a lo orgánico - antes que el resto de productores-, experimentando mucho éxito, que se reflejaba en la compra hace unos 5 años de un nuevo terreno, construcción de una nueva casa y viajes frecuentes afuera del país. Su éxito se debía a la labor y unión familiar, elementos un poco más espirituales que la adopción misma de los métodos orgánicos en un momento oportuno. Claro, puede ser que tenga razón, que la función familiar posibilite los ajustes necesarios para triunfar. El señor es un líder carismático, contaba abiertamente que "no pondría un pie en la tierra de Estados Unidos" por el desastre que ha hecho la política de Estados Unidos en Centroamérica y al medio ambiente. Así, con la cálida recepción que él transmite, casi cariñosa, recibe muchas visitas del extranjero para ver las operaciones de su finca como ejemplo de las mejores prácticas sostenibles (entrevistado 26, comunicación personal, noviembre de 2017).

Lo interesante de la historia de este agricultor y líder del movimiento de métodos orgánicos y sostenibles, igual que de varios de los otros entrevistados, es el hecho de promover la recepción de grupos, profesionales, turistas $y$ estudiantes nacionales o extranjeros a sus fincas. Esto lleva a otro elemento de adaptación aparte del tiempo, o más bien, otra categoría de adaptación sumamente importante: la adopción de elementos de educación y turismo en la finca. Otro agricultor que se dedicaba al cultivo de tomates prefirió hacer la entrevista en su campo, unas tierras rentadas a bajos precios por amigos que ya no vivían en el pueblo. La primera parte de la conversación se pasó demostrando el uso de trampas de feromonas que le permitían utilizar menos químicos en los tomates que vendía en la feria del agricultor que se encontraba afuera del pueblo, una feria que sirve como parada para varios grupos turísticos nacionales $y$ extranjeros que pasan por la zona $y$ donde muchos inmigrantes residentes hacen compras en la zona (entrevistado 11, comunicación personal, septiembre de 2017).

Es notable que la mayoría de las familias agricultoras expandía el rol de producción dentro de la finca en educar al público con diversas estrategias novedosas. Por ejemplo, un evento llamado "día de trabajo" que empezó con un desayuno y demostración de cocina sana, siguió con un tour, un almuerzo y terminó con una presentación sobre las aves nativas de esa zona. Se promovió el evento -que se repite 4 veces al año- como un día de trabajo en vez de un tour de finca, esto resultó en la llegada de turistas nacionales $y$ algunos internacionales. Sin embargo, al final resultó ser un evento de educación al consumidor, un tour en la finca, o sea, un evento de turismo (entrevistada 4, comunicación 
personal, agosto de 2017). En otro ejemplo, una joven dueña de una lechería regresó a la finca familiar con ideas innovadoras después de trabajar por unos años en una agencia de turismo en otro cantón del país, la finca era manejada por su mamá, una madre soltera con vocación agraria. Al regresar a la finca ambas trabajaron para expandir y mejorar la calidad de la leche $y$ queso producido por las 8 vacas que ordeñaban, con el fin de invertir en la expansión de los tours que organizaban dentro de la misma finca. Su experiencia previa en el campo del turismo y un trabajo actual, pero temporal, como guía turística en las zonas arqueológicas cercanas le daba acceso a las redes necesarias para levantar ese lado del negocio (entrevistada 23, comunicación personal, octubre de 2017). De tal forma que, estas dos fincas sobreviven por la integración de la producción con la venta de algunos productos de valor agregado, pero el producto que genera más valor es el turismo y la educación.

En Costa Rica, el turismo genera más ingresos por divisas que las exportaciones de los tres cultivos tradicionales juntos: banano, piña y café (Vindas, 2020), por lo tanto, acceder a los ingresos por el turismo es fundamental para la economía de una finca. Una agricultora, por ejemplo, unió fuerzas con su hermano que coordinaba eventos de meditación y yoga para integrar ambas actividades (entrevistada 32, comunicación personal, diciembre de 2017). Otro caficultor realiza tours, recibe grupos voluntarios en la finca y recientemente construyó una cabaña para alojar a los huéspedes de Airbnb (entrevistado 5, comunicación personal, agosto de 2017). Aunque varias personas comentaron que les interesaba expandir el negocio para vender los productos de valor agregado a manera de sacar más provecho de lo que siembran, lo que parece más rentable es vender la experiencia de la finca - como un valor agregadomás allá de vender los productos que siembran. Los ejemplos se observan en cualquier parte si alguien está de visita en el país, como cuando la primera autora y su familia buscaron hospedaje temporal mientras encontraban una casa para alquilar; la opción más inmediata fue una casita en una finca de café, y no era una opción inusual pues habían varias ofertas del mismo tipo de renta en la zona, muchas disponibles en plataformas de alquiler como Airbnb.

Hoy, la economía del agricultor familiar no solo requiere adaptaciones a nuevos mercados y turismo, sino también cierta flexibilidad en la integración de varios miembros de la familia que en otros contextos ha implicado nuevos roles para la mujer (Brandth, 2002; Brandth y Haugen, 2010; Hall y Mogyorody, 2007). En Costa Rica, cuando el hijo o la hija se integra al trabajo de la finca tiende a aportar nuevas visiones y estrategias sobre la labor agrícola. Una diferencia generacional evidente, por ejemplo, es que los más jóvenes muchas veces se dedican al turismo o a la producción de un producto de valor agregado, como el hijo de un caficultor que está produciendo y vendiendo vino de café, mientras su mamá y papá siguen dedicándose a las operaciones tradicionales de la siembra del cultivo (entrevistado 5, comunicación personal, agosto de 2017). Esa diferencia generacional de la labor familiar representa, en parte, la capacidad de ser flexible y visionario en los nuevos roles que adopta cada miembro de la familia bajo las condiciones estructurales que no permiten que la producción sea suficiente para mantener a la familia. Pero, también marca una gran diferencia de poder generacional en la labor familiar que merece más atención analítica.

\section{DISCUSIÓN}

En Costa Rica, como en otras partes del mundo, los pequeños agricultores familiares muchas veces demuestran un alto nivel de capacidad para la adaptación (Faure y Samper, 2004; Netting, 1993). El propósito de este artículo es explorar de forma cualitativa, las maneras en que algunos productores se adaptan al estado de la economía agrícola del siglo xxI. Específicamente, productores ubicados en una zona de interconexión urbana-rural del Occidente del Valle Central de Costa Rica, al identificar tanto las motivaciones como los significados de estos tipos de adaptaciones. A nivel macro, es una etapa marcada por la intensificación del cultivo y la integración de productos agrícolas costarricenses al mercado internacional a 
través de tratados de libre comercio. A la vez, a nivel local, la práctica comercial de los agricultores familiares entrevistados señala que el consumidor valora cada vez más el proceso de producción y la participación de la unidad familiar en este. Al enfrentar esta realidad cambiante, los testimonios de los entrevistados indican que existen dos tipos de adaptaciones destacadas, la primera, que implica la reducción de la dependencia económica de la familia a la producción agrícola y la segunda, que implica la expansión de operaciones de la finca fuera de la producción agraria. Esta no es una categorización cerrada o excluyente, podrían existir otro tipo de adaptaciones fuera del alcance de este estudio.

En el primer tipo de adaptación, algunos productores deciden disminuir la producción de la finca a una vocación de medio tiempo, a un pasatiempo o un trabajo de jubilación, pero no como fuente de ingreso principal. Aunque coloquialmente, muchos se quejan de que esta adaptación se debe a la falta de interés o falta de disponibilidad al trabajo duro de las nuevas generaciones o de los costarricenses en general (en contraste a los extranjeros nicaragüenses). La realidad empírica denota que no es así, existen ejemplos de hijos que quieren seguir con la producción agrícola de base familiar, pero simplemente no rinde económicamente como oficio principal. Los testimonios de los entrevistados indican que, a pesar de la inestabilidad económica que permea en la finca, ellos tratan de no rendirse, siguen considerándose como agricultores y su identidad está definida por esta labor. En otras palabras, estos agricultores no dejan de trabajar la tierra, aunque no dependen totalmente de la venta del producto, siempre buscan maneras de seguir participando en la producción agraria. Esta adaptación no la hacen como lo que Faure y Samper (2004) nombran como "una postura de defensa," hasta que las condiciones mejoren, ni como "una forma de permanencia," adaptándose a nuevas formas o tipos de productos. Una de las razones que les motiva a seguir como agricultores es la identidad cultural de agricultor familiar y una preferencia de estilo de vida que conecta a la unidad familiar y el medio ambiente. Esto sitúa centralmente a los valores de la familia, tal vez nostálgicamente, pero como una unidad productiva.

La otra adaptación a la nueva economía se caracteriza por una expansión de las operaciones y las definiciones del trabajo de la finca más allá de la producción de alimento, lo cual se manifiesta de dos diferentes maneras. Por un lado, un grupo que adoptó nuevas tecnologías como la hidroponía, todavía dedicándose mayormente a la producción de alimento con la incorporación de servicios de educación y marketing dirigido hacia las personas compradoras (con carteles y explicaciones bastantes detallados al consumidor o consumidora) en el mercado donde venden los productos. El otro grupo le otorgaba a su producto un valor agregado, cada día más valioso, el agroturismo y la educación. Atraían a los extranjeros o turistas nacionales a la finca misma, para que pudieran experimentar directamente no solo el producto, sino el proceso de producción. En este caso, al entrar en el mercado del turismo se involucra la integración de mercados nacionales y locales para los productos. En otras palabras, si en el pasado los productores familiares en el Valle Central adoptaron monocultivos, como el café, y la integración al mercado internacional a través de los acuerdos de libre comercio o los mercados alternativos internacionales, como Fair Trade. Ahora, para sobrevivir están enfocando su labor en generar productos dirigidos a nichos de mercado específicos o de valor agregado que pueden ser aprovechados tanto en los mercados locales, nacionales e internacionales, especialmente, por medio del turismo.

\section{CONCLUSIONES}

Teóricamente, lo novedoso de las adaptaciones destacadas anteriormente no es la flexibilidad laboral a la que se ven sometidos los agricultores familiares, una flexibilidad consecuente de la implementación de políticas económicas que van desde la agricultura del cambio hasta la implementación de los TLC donde se prioriza el mercado global. Lo novedoso, ciertamente, es una flexibilidad que debilita $y$ descentraliza al agricultor familiar que no puede sobrevivir exclusivamente de la 
agricultura misma. Como consecuencia, los que logran adaptar las operaciones de la finca a tiempo completo, lo hacen a través de la dinamización del mercado local, en oposición al proyecto político y económico que da ventaja a la producción dirigida al mercado exterior. Por lo tanto, la cooperación de todos los miembros de la familia se convierte en un proyecto agrícola cooperativo que representa una alternativa viable para mantener la vocación agrícola $y$ dinamizar la economía local. Sin embargo, para poder adaptarse efectivamente, los agricultores familiares se ven obligados a ingresar como novatos en un nuevo mercado que relaciona el valor agregado del producto con el turismo, muchas veces liderado por las generaciones más jóvenes de la familia, teniendo que hacerse espacio en un nuevo mercado donde el producto o, más bien, el servicio que más venden, es el turismo local. En este contexto, la participación en la toma de decisiones y la puesta en práctica de estrategias ligadas al agroturismo, comercialización, marketing y educación al consumidor sobre los productos agrícolas se convierten en una oportunidad para trascender tanto la producción agrícola de la finca como las prácticas culturales jerárquicas y patriarcales que han caracterizado la historia agraria latinoamericana (Chiappe, 2005; Menjívar, 2010).

Existen varias implicaciones empíricas, aparte del significado teórico sobre la capacidad de adaptación en el sector agrícola como organización económica flexible. Primero, el agricultor familiar en la zona occidental del Valle Central de Costa Rica se encuentra en una situación aparentemente no sostenible, o tienen que dejar la agricultura como vocación a tiempo completo $y$ reducirla a un tiempo limitado, o expandir la definición y el trabajo fuera de la producción agropecuaria principal de la finca. Segundo, ambas opciones implican transformaciones contundentes en las prácticas de la agricultura en el seno familiar, lo que indica que cualquiera que sea la decisión que se considere, habrá una interrupción en los hábitos que han sostenido la economía de la unidad familiar, tanto en las relaciones de género como intergeneracionales. Esto supondría la participación protagonista de las personas jóvenes $y$ las mujeres, lo cual tiene implicaciones culturales para el país y la región centroamericana. Estos procesos de cambio se podrían considerar como elementos unificadores y consecuentes con los valores familiares que destacaron los entrevistados. Tercero, las unidades muestrales $y$ otras familias en similares condiciones dentro de la región del Valle Central se ven sometidas a presiones en virtud de los ajustes necesarios para su sobrevivencia, formas de presión que representan, en cierta medida, un desafío de base local contra la integración vertical de los mercados agrícolas que ha logrado reducir los espacios de participación del pequeño productor y sentar las condiciones que debilitan la economía familiar. Por lo tanto, la presión que enfrentan los agricultores familiares en términos estructurales produce diversas reacciones, entre ellas, la que consolida una forma de resistencia contra la organización agrícola del mercado global, mientras sienta las bases de un modelo de resistencia de la economía familiar.

Ciertamente, como resultado de la presión del campesino por el acceso a la tierra y la exigencia de políticas de redistribución de la tierra en el siglo xx, se obtuvo la apropiación de ciertas tierras para pequeños productores, un proceso sin precedentes en la región centroamericana. Fue un logro alcanzado por la lucha social y un estado dispuesto a promover políticas de redistribución que beneficiaran al pequeño agricultor y lo integraran al desarrollo económico agrícola del país. Sin embargo, la realidad que enfrenta la agricultora familiar en la actualidad da cuenta de la negligencia en su atención frente a la actual política agraria y los tratados de libre comercio, que ahora se ve entre la espada y la pared, obligada a asumir una salida tanto incierta como novedosa, forzándola a generar formas de valor alternativas a la producción agropecuaria familiar inicial. Este tipo de agricultura enfrenta presiones para tomar una decisión que les permita sobrevivir como unidad de producción agrícola, toparse frente a la pared, que implica detenerse sin encontrar salida o enfrentarse a los cambios (la espada) de forma creativa, asumiendo el riesgo que implica ajustarse a nuevos modelos de desarrollo económico que en este caso trasciende 
la agricultura y se internan en nuevos mercados $y$ formas de valor.

\section{REFERENCIAS}

Alvarado, L. (2018). Deliberar la política de desarrollo rural territorial costarricense. Perspectivas Rurales Nueva Época, 16(32), 89-119.

Arias, O. (2005). Retos para la agricultura em Costa Rica. Agronomía Costarricense, 29(2), 157-166.

Dreby, J., Gowoon, J. y Sullivan, R. (2017). At the Nexus of Work and Family: Family Farms in Upstate New York. Journal of Rural Studies, 49, 151-161.

Dreby, J. y Mairead, C. (2019). The Social Value of Children for Families that Farm. Sociological Forum, 34 (4), 904-925.

Babin, N. (2015). The Coffee Crisis, Fair Trade, and Agroecological Transformation: Impacts on Land-Use Change in Costa Rica. Agroecology and Sustainable Food Systems, 39 (1), 99-129.

Bailey, C., Jensen, L. y Ransom, E. (2014). Rural America in a Globalizing World: Introduction and Overview. En Conner Bailey, Leif Jensen y Elizabeth Ransom (eds.), Rural America in a Globalizing World (pp. vii-xxx). West Virginia University Press.

Brandth, B. (2002). Gender identity in European family farming: a literature review. Sociol. Rural, 42 (3), 181-199.

Brandth, B. y Haugen, M. S. (2010). Doing Farm Tourism: The Intertwining Practices of Gender and Work. Signs 35(2), 425-446.

Caamaño Morúa, C. (2010). Entre "Arriba" y "Abajo": la experiencia transnacional de la migración de costarricenses hacia Estados Unidos. Editorial de la Universidad de Costa Rica.

Carlson, A. (2008). Agrarianism Reborn: On the Curious Return of the Small Family Farm. Intercollegiate Review, 43 (1), 13-23.

Chiappe, M. (2005). La situación de las mujeres rurales en la agricultura familiar de cinco países de América Latina. Informe de la Asociación Latinoamericana de Organizaciones de Promoción. Montevideo, Uruguay.

Clark, M. (1997). Transnational Alliances and Development Policy in Latin America: Nontraditional Export Promotion in Costa Rica. Latin American Research Review, 32(2), 71-97.

Constance, D. H., Hendrickson, M., Howard, P. H. y Heffernan, W. D. (2014). Economic Concentration in the Agrifood System: Impacts on Rural Communities and Emerging Responses. En Conner Bailey, Leif Jensen y Elizabeth Ransom (eds.), Rural America in a Globalizing World (pp. 16-35). West Virginia University Press.

Conway, S.F., McDonagh, J., Farrell, M. y Kinsella, A. (2017). Uncovering obstacles: The exercise of symbolic power in the complex arena of intergenerational family farm transfer. Journal of Rural Studies, 54, 60-75.

Deere, C. D. y León, M. (2003). The gender asset gap: Land in Latin America. World development, 31(6), 925-947.

Edelman, M. (1999). Peasants against Globalization: Rural Social Movements in Costa Rica. Stanford University Press.

Faure, G. y Samper, M. (2004). Veinte años de apertura económica: el porvenir comprometido de la agricultura familiar en el norte de costa rica. Anuario De Estudios Centroamericanos, $30(1 / 2), 7-26$.

Fernández, M. E. (1984). Desarrollo capitalista y formas productivas en el agro: la producción cafetalera, el caso de la zona Alajuela, Grecia (No. 4). Universidad de Costa Rica, Facultad de Ciencias Sociales, Instituto de Investigaciones Sociales.

Fernández, M. E. (1989). Acceso y reproducción del campesinado en Costa Rica y producción campesina. Revista de Ciencias Sociales, 31-41.

Gingrich, C. y Garber, J. (2010). Trade Liberalization's Impact on Agriculture in 
Low Income Countries: A Comparison of El Salvador and Costa Rica. The Journal of Developing Areas, 43(2), 1-17.

Gray, M. (2013). Labor and the Locavore. University of California Press.

Hall, A. y Mogyorody, V. (2007). Organic farming, gender, and the labor process. Rural Sociology, 72 (2), 289-316.

Hartley Ballestero, M. (2010). Sostenibilidad de la Caficultura de Baja Altura: análisis de una paradoja. Revista de Ciencias Económicas, 28(1), 101-114.

Hendrickson, M., Howard, P. H. y Constance, D. (2017). Power, Food and Agriculture: Implications for Farmers, Consumers and Communities. University of Missouri. College of Agriculture, Food \& Natural Resources Division of Applied Social Sciences Working Paper.

Inwood, S. y Sharp, J. (2012). Farm Persistence and Adaptation at the Rural-Urban Interface: Succession and Farm Adjustment. Journal of Rural Studies, (28) 1, 107-117.

Inwood, S., Clark, J. K. y Bean, M. (2013). The Differing Values of Multigeneration and First-Generation Farmers: Their Influence on the Structure of Agriculture at the Rural-Urban Interface. Rural Sociology, 78 (3), 346-370.

Martínez-Franzoni, J. y Castro, M. (2004). El TLC y el empleo en Costa Rica. TLC con los Estados Unidos. Contribuciones para el debate. ¿Debe Costa Rica aprobarlo? Editorial de la Universidad de Costa Rica.

Menjívar, M. (2010). Niños que se hacen hombres: Conformación de identidades masculinas de agricultores en Costa Rica. Revista Latinoamericana de Ciencias Sociales, Niñez y Juventud, 8(2), 995-1012.

Mora-Alfaro, J. (1987). Crisis y movimientos campesinos en Costa Rica. 1978-1986. Revista Abra, 6(5), 137-186.

Mora-Alfaro, J. (1989). Costa Rica: agricultura de cambio y producción campesina. Revista de Ciencias Sociales, 43, 7-29.

Mora-Alfaro, J. (2005). Agrarian policies and rural development in Costa
Rica: definitions elements in the new international context. Agronomía Costarricense, 29(1), 101-133.

Mora-Alfaro, J. (2013). Desarrollo rural y ciudadanía social: Territorios, instituciones $y$ actores locales. FLACSO Costa Rica. http:// biblioteca.clacso.edu.ar/Costa_Rica/flacso-cr/20170704034945/pdf_184.pdf

Morales, N. y Segura, R. (2014). Distribución de la tierra y su relación con la desigualdad social. [Ponencia] Simposio del Censo Nacional Agropecuario.

Netting, R. (1993). Smallholders, Householders: Farm Families and the Ecology of Intensive, Sustainable Agriculture. Stanford University Press.

Pacheco, A. (2004). Información, consulta y participación en el proceso de negociación. En María Flórez-Estrada Pimentel y Gerardo Hernández Naranjo. (Eds), TLC con Estados Unidos: contribuciones para el debate. ¿Debe Costa Rica aprobarlo? (pp. 25-36). Instituto de Investigaciones Sociales, Universidad de Costa Rica.

Paz, R., Rodríguez-Sperat, R., González, V. y Liphsitz, H. (2011). Producción económica en una pequeña explotación lechera caprina: hacia un diseño alternativo de desarrollo rural. Revista Asociación Latinoamericana de Producción Animal, 18 (3-4), 97-111.

Paige, J. M. (1997). Coffee and Power: Revolution and the Rise of Democracy in Central America. Harvard University Press.

Pilgeram, R. (2011). "The only thing that isn't sustainable... is the farmer": social sustainability and the politics of class among Pacific Northwest farmers engaged in sustainable farming. Rural Sociology, 76 (3), 375-393.

Programa Estado de la Nación (2017). El TLC y sus impactos 10 años después de su aprobación [2017]. San Jose, Costa Rica. https://www. tlc.estadonacion.or.cr/documentos/modulo-4/Informe-entrevistas.pdf

Redacción Universidad (4 de octubre de 2017). Diez años de TLC en Telecomunicaciones. Semanario 
Universidad. https://semanariouniversidad.com/opinion/diez-anos-tlc-telecomunicaciones/

Renting, H., Marsden, T. K. y Banks, J. (2003). Understanding alternative food networks: exploring the role of short supply chains in rural development. Environment and planning, 393-411.

Robinson-Davis, W. R. (1987). Desarrollo y los límites agrícolas. Revista ABRA, 7(7-8), $135-158$.

Rodriguez, A., Sáenz-Segura, F., Arias, L. y Le Coq, J. F. (2018). Políticas para la agricultura familiar en Costa Rica. Raizes: Revista de Ciências Sociais e Econômicas, 38(1), 51-64.

Rodríguez Sperat, R., Paz, R. G., Suarez, M. V. y Díaz, J. P. (2015). Construyendo mercados desde la propia finca. Tres experiencias en la agricultura familiar. Agro Sur, 43(1), 3-17. https://doi.org/10.4206/ agrosur.2015.v43n1-02

Rojas, M. (1989). Cooperativas agrícolas de la región Chorotega: extensión, tenencia, uso y situación jurídica de la tierra y producción campesina. Revista de Ciencias Sociales 43, 43-51.

Sabourin, E., Samper, M. y Sotomayor, O. (2015). Políticas públicas y agriculturas familiares en América Latina y el Caribe. San José, Costa Rica. https://agritrop. cirad.fr/578798/1/chap_578798.pdf

Samper, M. (2010). Costa Rica's Response to the Coffee Crisis. Latin American Perspectives, 37(2), 72-92.

Samper, M. (2016). Sistemas territorialies de agricultura familiar. Sistema de Gestion Estrategica para el Desarrollo Territorial y la Agricultura Familias. Instituto
Interamericao de Cooperacion para la Agricultura. http://repiica.iica.int/docs/ B4236e/B4236e.pdf

Schor, J. y Thompson, C. J. (2014). Sustainable Lifestyles and the Quest for Plenitude: Case Studies of the New Economy. Yale University Press.

Schor, J. (2011). True Wealth: How and Why Millions of Americans Are Creating a Time-rich, Ecologically light, Smallscale, High-satisfaction Economy. The Penguin Press.

Sick, D. (2008). Coffee, Farming Families, and Fair Trade in Costa Rica: New Markets, Same Old Problems? Latin American Research Review, 43(3), 193-208.

Thu, K. (2009). The centralization of food systems and political power. Cult. Agric., 31, 13-18.

Vargas, E. (2004). Implicaciones del TLC desde la perspectiva de la agricultura familiar campesina. En María Flórez-Estrada Pimentel y Gerardo Hernández Naranjo (Eds), TLC con Estados Unidos: contribuciones para el debate. ¿Debe Costa Rica aprobarlo? (pp 249-270). Instituto de Investigaciones Sociales, Universidad de Costa Rica.

Vindas, S. B. (2020). El aporte del turismo a la economía costarricense: más de una década después. Economía y Sociedad, 25(57), 1-29.

Voorend, K. y Robles Rivera, F. (2011). Migrando en la crisis: La fuerza de trabajo inmigrante en la economía costarricense. Ministerio de Trabajo y Seguridad Social.

Fecha de ingreso: 25/08/2020 Fecha de aprobación: 02/09/2021 
